\title{
Pascal Boniface, Football et mondialisation
}

Paris, A. Colin, coll. Cursus, $2^{\mathrm{e}}$ éd., 2010

\section{Amina Lasfar}

\section{(2) OpenEdition}

\section{Journals}

Édition électronique

URL : http://journals.openedition.org/questionsdecommunication/2841

DOI : 10.4000 /questionsdecommunication.2841

ISSN : 2259-8901

\section{Éditeur}

Presses universitaires de Lorraine

\section{Édition imprimée}

Date de publication : 30 juin 2011

Pagination : 370-372

ISBN : 978-2-8143-0084-2

ISSN : 1633-5961

\section{Référence électronique}

Amina Lasfar, « Pascal Boniface, Football et mondialisation », Questions de communication [En ligne], 19 | 2011, mis en ligne le , consulté le 10 décembre 2020. URL : http://journals.openedition.org/ questionsdecommunication/2841 ; DOI : https://doi.org/10.4000/questionsdecommunication.2841

Ce document a été généré automatiquement le 10 décembre 2020.

Tous droits réservés 


\section{Pascal Boniface, Football et mondialisation}

Paris, A. Colin, coll. Cursus, $2^{\mathrm{e}}$ éd., 2010

Amina Lasfar

\section{RÉFÉRENCE}

Pascal Boniface, Football et mondialisation, Paris, A. Colin, coll. Cursus, $2^{\mathrm{e}}$ éd., 2010, 223 p.

1 Armé de ses analyses géopolitiques, de sa grande passion pour le ballon rond et de certains travaux sociologiques portant sur le sport en général, le football en particulier, Pascal Boniface invite, par cette contribution sous forme d'essai, à faire le tour de «la planète foot » et découvrir les paradoxes d'un empire populaire qui « ne connaît ni limites ni frontières » (p. 21). À la fois « mondialisé et enraciné » (p. 60), l'auteur précise que le football peut être source de passions collectives destructrices ou vecteur d'intégration sociale et de fraternité entre les peuples. S'intéresser aux paradoxes du football permet à l'auteur de recenser et dénoncer les dérives de ce sport, et ce, pour mieux le défendre. En effet, pour Pascal Boniface, Football et mondialisation constitue l'occasion de fustiger le mépris de certains intellectuels à l'égard du football, à commencer par ses propres collègues de l'Institut international de relations internationales (IRIS) qu'il dirige. Ainsi l'auteur décrit-il, dans l'introduction de cet ouvrage, l'attitude de ses collaborateurs quand il a exprimé son intention d'organiser une rencontre universitaire sur ce thème : « Mes collègues me regardent avec beaucoup de peine, pensant sans doute que je poussais le sens de la galéjade un peu trop loin " (p. 14). Selon lui, cette attitude traduit une certaine peur des passions qui entourent le football alors qu'elles ne sont pas, estime-t-il, «plus malsaines que celle qui entourent les débats sur le Proche-Orient, l'Afghanistan, le choc des civilisations, l'identité nationale» (p.10). Cette posture révèle également le mépris du jeu et des joueurs considérant les footballeurs comme des «idiots» ou des «imbéciles» et leurs supporters comme des « beaufs » ou des « meutes alcoolisées ». 
2 L'un des premiers paradoxes auxquels s'attaque Pascal Boniface dans le chapitre 2 («Stade suprême de la mondialisation », p. 21) et le chapitre 3 («Les champions de l'identité nationale », p. 59), concerne la dialectique de la mondialisation et de l'identité nationale. Loin de dissoudre les identités nationales, la mondialisation du football les renforce. L'auteur revient sur les raisons du succès planétaire de cette pratique sportive. Il explique comment elle a su conquérir d'une manière pacifique, et par simple adhésion, l'ensemble de la planète, y compris les monastères tibétains les plus austères. Typiquement britannique, n'exigeant ni équipements particuliers ni grands investissements financiers, ce sport se prêterait facilement à la théâtralisation et la dramatisation. La planète devient ainsi « un stade unique dans lequel chacun peut trouver sa place» (p.33) grâce, notamment, au «mariage de la télévision et du football» (p.31). Demeure cependant une exception, celle de la société états-unienne où le football, associé aux migrants, n'a pas su trouver sa place dans une société où l'intégration se fait par l'adoption des jeux nationaux. Dans cette analyse sur les usages universels du football, on peut regretter que l'auteur fasse l'économie des modalités de réappropriation et d'adaptation de cette pratique dans des contextes socioculturels différents (modalités génératrices d'ailleurs de nouvelles formes de productions culturelles).

3 Par ailleurs, Pascal Boniface n'explique pas pourquoi le football, sport universel par excellence, reste d'abord une pratique masculine qui transcende les clivages socioculturels et les appartenances nationales. Mais si le football constitue le «stade suprême de mondialisation", il reste, souligne Pascal Boniface, un marqueur identitaire fort. Le football, précise-t-il, consolide aussi bien les identités nationales plus particulièrement dans des états où le sentiment d'appartenance nationale est fragile, comme la Belgique - que les identités régionales et locales - notamment en Espagne où le football a joué un rôle important dans les relations entre les régions et l'État central. La force des liens entre football et identité nationale explique, par exemple, pourquoi la FIFA (Fédération internationale du football) accepte en son sein (à la différence de l'oNu) des entités sans États (Palestine, Polynésie française, les îles Féroé, Taïwan). Elle explique également que l'Angleterre, l'Écosse, l'Irlande du nord et le Pays de Galle refusent catégoriquement l'idée même de la création d'une unique équipe nationale britannique. Ainsi, insiste l'auteur, le football peut-il permettre aux petites nations ou aux nations oubliées de s'affirmer sur le plan international. De ce fait, il faut se réjouir de l'organisation de la coupe du monde 2010 en Afrique du Sud. Cette initiative, précise-t-il, met à l'honneur non seulement l'Afrique du Sud mais l'ensemble du continent africain (voir chapitre 1, « Une coupe pour l'Afrique », p. 17). Cependant, l'auteur ne précise pas comment on peut mesurer concrètement le rayonnement des états par le football. Néanmoins, selon Pascal Boniface, le football marqueur identitaire fort - reste un sport «ouvert» et "accueillant»: il peut non seulement renforcer l'identité européenne - via la circulation des joueurs dans l'espace européen, la retransmission des matchs et le soutien des équipes étrangères par certains fans -, mais également œuvrer pour le rapprochement entre les peuples, voire initier le grand public aux questions internationales. Cependant, reconnaît l'auteur, cette ouverture au monde n'exclut nullement le déchainement des passions collectives génératrices de repli identitaire, de violence et d'exclusion. Pascal Boniface recense et dénonce toutes les dérives possibles, à savoir l'instrumentalisation politique (chapitre 5, «Le nouvel opium du peuple »), la violence (chapitre 4, "Le Mondial plutôt que la guerre mondiale ») et le racisme (chapitre 7, «Football et racisme : le mouchoir et les 
larmes »).Toutefois, si l'auteur dénonce ces dérives, il s'évertue, par la même occasion, à préciser que ces déviances ne font que refléter les maux de la société.

Avec ce postulat, Pascal Boniface s'attaque au discours critique radical développé par des sociologues « anti-sport " (Patrick Vassort et Jean-Marie Brohm). Il réfute la thèse qui considère le football comme un «nouvel opium du peuple » ayant, pour finalité, de divertir le peuple pour le détourner de ses propres intérêts économiques et politiques. Il réfute également le postulat associant le football à " un appareil idéologique d'État » œuvrant pour la désintégration sociale, l'abrutissement populiste et le déferlement de la violence et du racisme. D'abord, précise l'auteur, l'instrumentalisation politique n'atteint pas toujours ses buts. À titre d'exemple, il cite les tentatives avortées de la gente militaire argentine (profiter de l'organisation de la coupe du monde en 1978 pour donner une image positive du régime à l'extérieur) et celles du gouvernement mexicain (utiliser la coupe du monde de 1986 pour améliorer son image auprès de la population). $\mathrm{Au}$ contraire, affirme-t-il, le stade de football peut devenir un « lieu de contestation du pouvoir où la répression peut difficilement s'organiser " (p. 132). C'était le cas pour l'empereur romain, rappelle-t-il, c'est le cas aujourd'hui pour le Président français Nicolas Sarkozy. Ensuite, Pascal Boniface réfute la thèse qui accuse le football d'être à l'origine de conflits internationaux comme certains l'ont laissé croire pour élucider les causes de la guerre entre le Salvador et le Honduras en 1969. Pour corroborer cette thèse, il prend appui sur les travaux de Norbert Elias, relatifs à la genèse de l'État moderne et au procès de civilisation (transformation des mœurs marquée par l'autocontrôle des pulsions dans des sociétés où l'état détient le monopole de la violence légitime). L'auteur précise que l'association du football et de la guerre relève plus du domaine symbolique. Elle concerne les rituels (levée de drapeaux, hymnes nationaux) et les métaphores guerrières utilisées pour commenter les rencontres sportives. Ainsi les manifestations sportives permettraient-elles «aux représentants des différentes nations de s'affronter sans s'entretuer" et aux spectateurs de "savourer l'excitation mythique d'une bataille qui se déroule sur le stade et savoir qu'aucun mal ne sera fait aux joueurs ni à eux-mêmes» (pp.125-126). Les «transformations de tels simulacres en combats réels sont fonctions, entre autre, de niveau de tension préexistant entre les états-nations concernés » (p. 124). Loin d'être à l'origine de certains conflits internationaux, Pascal Boniface estime que le football peut être au contraire «le lieu des gestes positifs symboliques, qui ont pu contribuer, plus que de longs discours ou que certaines résolutions internationales, à la progression vers une résolution pacifique de certains conflits civils ou internationaux» (p. 107), à l'instar du rapprochement du Japon et de la Corée du Sud, ou celui de la Turquie et de l'Arménie.

5 Enfin, si le football peut être un vecteur de fraternité entre les peuples, il peut également jouer un rôle important dans la lutte contre le racisme. Sans nier les manifestations racistes qui gangrènent le monde du football et les discriminations qui touchent les joueurs de couleur - visibles par leur absence des instances de direction des clubs et des fédérations-, Pascal Boniface met en avant l'importance et l'exemplarité des combats menés par les instances du football pour lutter contre le racisme et la violence: les clubs sont désormais responsables de l'attitude de leurs supporters et des sanctions peuvent être prononcées en cas de débordements violents ou racistes. Le football serait même un exemple en matière d'intégration et de reconnaissance de la diversité. Pascal Boniface note qu'il est plus facile pour un joueur de couleur d'être footballeur international dans une équipe où il y a 11 places que 
député dans une assemblée où il y a 577 titulaires. L'empathie de l'auteur à l'égard de son objet laisse transparaître ici une vision quelque peu idyllique du monde du football. En effet, loin d'être de simples dérives qu'il faudra combattre, les phénomènes de racisme et de violence peuvent revêtir, dans des configurations socioculturelles particulières, une dimension purement structurelle. Dans le chapitre 6 («Qui gouverne le football », p. 157), l'auteur aborde les enjeux économiques et financiers du football, et critique l'emprise de la logique libérale sur le monde du football. Il ajoute que cette logique qui s'est renforcée par la place grandissante des sponsors et des médias affaiblit le pouvoir des fédérations du football au profit des clubs les plus riches.

6 À cet égard, Pascal Boniface s'attaque aussi à l'arrêt Bosman (Cour européenne, 11/12/1995) qui aurait accentué cette logique libérale dans l'espace européen. S'il se réjouit qu'il permette la libre circulation des joueurs qui ne sont plus contraints de passer toute leur carrière dans le même club, il regrette la fin de la limitation du nombre des joueurs communautaires dans les clubs européens. Selon l'auteur, cet arrêt constitue un désastre. Il participe au processus de déterritorialisation du football et permet la concentration du pouvoir, de l'argent et des talents entre les mains des quelques clubs, les plus riches et les plus puissants. Ces derniers, constate-t-il, peuvent désormais dicter leur loi et développer des stratagèmes afin de contourner certains règlements de la FIFA. Pour pouvoir disposer de joueurs pour les compétitions internationales, les sélectionneurs nationaux doivent ainsi engager un bras de fer permanent avec les managers des clubs, ce qui accentue, au niveau international, les clivages entre les pauvres et les riches, entre le Nord et le Sud.

\section{AUTEURS}

\section{AMINA LASFAR}

CRAPE, université catholique de l'Ouest

amina.lasfar@uco.fr 